Article

\title{
Assessment of the Design for Assembly processes using fuzzy logic
}

\author{
Józef Matuszek $^{1 *}$, Tomasz Seneta ${ }^{1}$ and , Aleksander Moczała ${ }^{1}$ \\ 1 University of Bielsko-Biala, Faculty of Mechanical Engineering And Computer Science, Willowa 2, 43-309 \\ Bielsko-Biała, Poland,jmatuszek@ath.bielsko.pl, tomasz.seneta@zf.com, amoczala@ath.bielsko.pl; e-mail@e- \\ mail.com \\ *Correspondence: jmatuszek@ ath.bielsko.pl; Tel.: +48-338279253
}

Featured Application: new method for assessing design for manufacturability based on fuzzy variables.

\begin{abstract}
The paper presents methodology for designing the production process of a new product from the point of view of the assembly operations technology criterion (Design for Assembly - DFA) in the conditions of high-volume production. Mentioned are DFA methods and techniques used in the implementation of a new product. Author presents a new method for assessing design for manufacturability based on fuzzy variables based on fuzzy variables. An example was given to illustrate the proposed course of action
\end{abstract}

Keywords: production process design, design for manufacturability, fuzzy logic.

\section{Introduction}

In today's market conditions, the company introducing new products to the production, use different methods and techniques to rationalize actions that make up the concept of pre-production. The issue has a rich literature, different philosophies are presented there to rationalize the production process sequences, for example. Six Sigma, Lean, WCM, Target Costing $[1,15,23]$.

In the conditions of high production volume, when implement new products, less attention is due to the ever-wider technological possibilities of contemporary workplaces, workshop aids, automation, the high performance achieved and relatively low costs, devoted to the processing of elements, components of final products. Hence reported in literature advanced evaluation methods of products design manufacturability tailored to evaluate the implementation of a new product in the conditions of high volume mass production and are directed to processes for assembly. This is due to the high proportion of manual work compared to machining, which is associated with high labour intensity and high costs of assembly processes.

In the production of individual and small-batch main attention is paid to the issue of the possibility to implement in the plant, the possibility of cooperative companies, as well as the determinants of the logistic flow of resources. Therefore, much attention is paid to the performance of the production cost target, taking into account investments in new production lines and positions, defined in terms of having to be carried out also other products and vision of the future production program $[7,9,17]$.

\section{Production preparation process}

In the automotive industry, proposals for the use of design-oriented assessment methods for assembly. "Design for Assembly" - DFA, was described by G. Boothroyd and P. Dewhurst in the work "Design for Assembly, A Designers Handbook" in 1983. The concept of "Design for Assembly" can be defined in various ways, from the narrow meaning of "product design from the point of view of manufacturability criterion" to the broader term associated with "product and process design from the cost-effective criterion point of view and reliable manufacturing to ensure the state of customer 
satisfaction "[18]. Many DFA methods are presented in the literature. The chronology of these methods and their brief characteristics are presented in Table 1. [16].

Table 1. Summary and description of the methodology of selected Design of Assembly methods [16].

\begin{tabular}{|c|c|c|c|c|}
\hline $\mathrm{Nr}$ & Metoda & Rok & Odkrywcy & Opis \\
\hline 1. & Lucas DFA & 1980 & $\begin{array}{l}\text { Redford A. H., } \\
\text { Swift K. G. }\end{array}$ & $\begin{array}{l}\text { It is based on the assembly sequence } \\
\text { diagram (SSM) that assess the assembly } \\
\text { design. Producibility is estimated based } \\
\text { on penalty points associated with the } \\
\text { product installation problems. }\end{array}$ \\
\hline 2. & $\begin{array}{c}\text { Hitachi } \\
\text { Assemblability } \\
\text { Evaluation Method } \\
(\mathrm{AEM})\end{array}$ & 1986 & $\begin{array}{l}\text { Miyagawa S., } \\
\text { Ohashi T. }\end{array}$ & $\begin{array}{l}\text { The method assesses the product's } \\
\text { assemblability and the cost index to } \\
\text { indicate project weaknesses. }\end{array}$ \\
\hline 3. & $\begin{array}{l}\text { Product } \\
\text { Assemblability Merit } \\
\text { Analysis Tool (PDM) }\end{array}$ & 1986 & Zorowski C. F. & $\begin{array}{c}\text { The method gives opinions on product } \\
\text { and component assembly problems and } \\
\text { oversize indicators in the project. }\end{array}$ \\
\hline 4. & $\begin{array}{l}\text { Boothroyd and } \\
\text { Dewhurst }\end{array}$ & 1988 & $\begin{array}{l}\text { Boothroyd G., } \\
\text { Dewhurst P. }\end{array}$ & $\begin{array}{l}\text { The method is based on determining the } \\
\text { costs associated with the manual or } \\
\text { automatic assembly process and has } \\
\text { three criteria to limit the number of } \\
\text { components. }\end{array}$ \\
\hline 5. & $\begin{array}{l}\text { Integrated Design for } \\
\text { Assembly Evaluation } \\
\text { and Reasoning System }\end{array}$ & 1991 & $\begin{array}{l}\text { Sturges R. H. } \\
\text { Jr, Kilani M. I. }\end{array}$ & $\begin{array}{l}\text { The method built based on solid } \\
\text { modelling, explores the possibility of } \\
\text { product assemblability. }\end{array}$ \\
\hline 6. & $\begin{array}{c}\text { Fuzzy Product } \\
\text { Assemblability Merit } \\
\text { Analysis Tool } \\
\end{array}$ & 1993 & $\begin{array}{l}\text { Jackson S. D., } \\
\text { Sutton J. C., } \\
\text { Zorowski C. F. }\end{array}$ & PDM developed with fuzzy logic. \\
\hline 7. & DFA REV-ENGE & 1994 & $\begin{array}{l}\text { Kim G. J., } \\
\text { Bekey G. A. }\end{array}$ & $\begin{array}{c}\text { DFA method taking into account } \\
\text { reverse engineering. }\end{array}$ \\
\hline 8. & $\begin{array}{l}\text { Constraints Network } \\
\text { System }\end{array}$ & 1995 & $\begin{array}{l}\text { Oh J. S., Grady } \\
\text { P. O., Young } \\
\text { R. D. F. }\end{array}$ & Method of interrelated constraints. \\
\hline 9. & $\begin{array}{l}\text { Virtual Disassembly } \\
\text { Evaluation }\end{array}$ & 1998 & Srinivasan $\mathrm{H}$. & $\begin{array}{l}\text { Method taking into account virtual } \\
\text { disassembly. }\end{array}$ \\
\hline
\end{tabular}

The first and the second method are presented in the paper, due to the largest application in practice. Market conditions have forced companies to rationalize a comprehensive approach to the design and marketing of a new product [2,4,5,23]. The need for a broader look at the assessment of the technology of the structure, including this problem, take into account many other aspects, this way of design is illustrated in Fig. 1. 


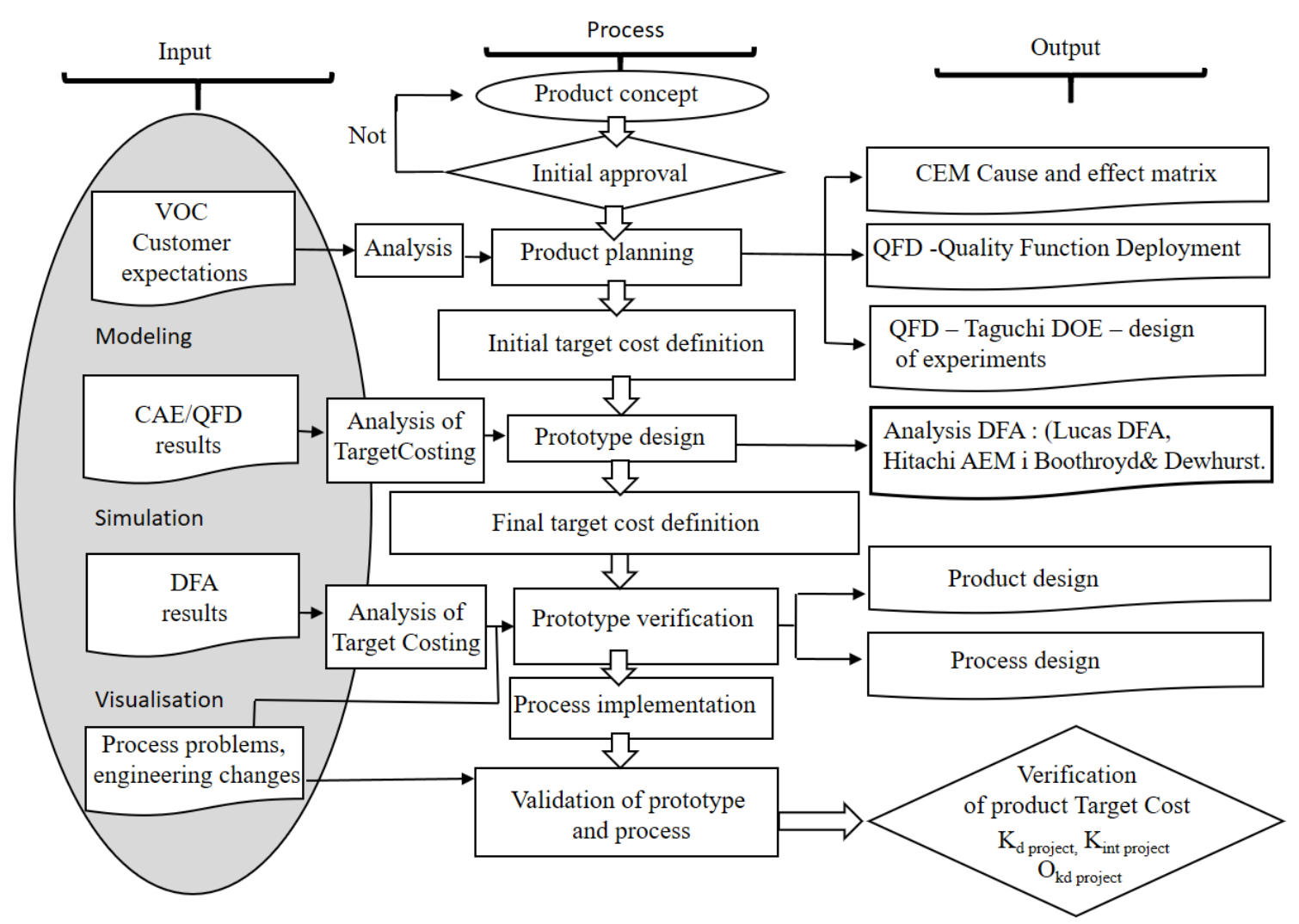

Figure 1. The use of methods that support design of the production process of a new product.

In the design process under the aforementioned philosophies have been used methods such as QFD (Quality Function Deployment) $[1,10,13]$ use in processes of implement products customer requirements, FMEA (Failure Mode and Effect Analysis) [19] - related to the prediction and prevention of problems at the product design stage, DFX (Design for X) [23] - e.g. Design for Manufacturing (DFM) regarding the shaping of the design process of components and the product itself [6]. Decisions taken at the product design stage have a significant impact on production costs, efficiency and quality of production. Supporting methods such as modelling, simulation and animation of production processes and systems as well as stimulating innovation such as brainstorming, TRIZ is of great importance in carrying out these works.

\section{Methods of assembly manufacturability assessment}

This section may be divided by subheadings. It should provide a concise and precise description of the experimental results, their interpretation as well as the experimental conclusions that can be drawn.

\subsection{Lucas DFA method}

The method was developed in 1980 by Lucas and University of Hull research teams. The method is used for manual or automatic assembly analysis. The method includes aims to reduce the number of components of the final product, the use of shape the structure of components to facilitate assembly. In the Lucas DFA method, three indicators determine the measure of mounting difficulty.[21] The procedure is as follows. The prepared project is subjected to functional analysis, which determines whether individual components are needed and what their functions are - fig. 2. 


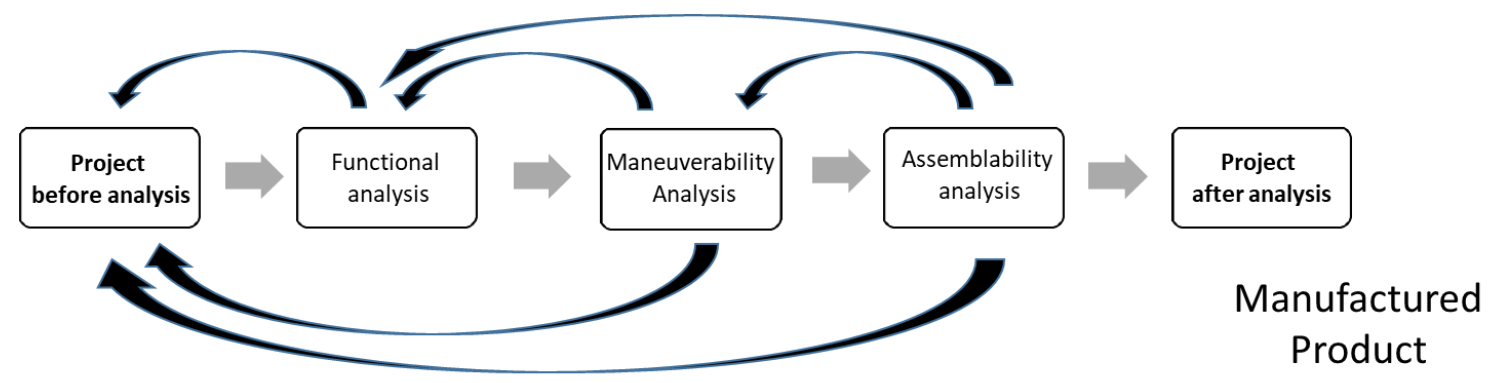

Figure 2. Procedure in the LUCAS Design for Assembly method

A feasibility analysis is then made up consisting of manoeuvring analysis and assembly analysis. Data for analysis can be read for specific installation conditions from the tables. Formulas that describe the results of the analysis in the LUCAS DFA method are:

The project efficiency index based on functional analysis is determined by the formula

$$
\mathrm{W}_{\mathrm{ep}}=\frac{\mathrm{L}_{\mathrm{kA}}}{\left(\mathrm{L}_{\mathrm{kA}}+\mathrm{L}_{\mathrm{kB}}\right)} \times 100 \%
$$

where: $\mathrm{W}_{\mathrm{ep}}$ - project efficiency index, $\mathrm{LkA}_{\mathrm{k}}$ - number of A components (fulfill product functions), L $k B$ - number of B components (characterized by lack of fulfill product functions, e.g. rivets, washers).

Based on the analysis carried out in this way, it is possible to combine some separate components into one whole, thus reducing the number of individual components that make up the final product, change the design solutions that eliminate components that do not fulfill the function of the product. Then, an analysis is carried out consisting of an analysis of the displacement of the mounted components, their maneuvering and the method of assembly itself. [21] The maneuvering assessment of the assembled product components is determined on the basis of fig. 8 .

The $\mathrm{W}_{\operatorname{man}}$ maneuvering factor is given by the formula:

$$
\begin{gathered}
W_{\text {man }}=I_{\text {man }} / L_{k A} \\
I_{\text {man }}=L_{p A}+L_{p B}+L_{p C}+L_{p D}
\end{gathered}
$$

where: $\mathrm{W}_{\text {man }}$ - maneuvering coefficient, $\mathrm{I}_{\mathrm{man}}$ - maneuvering index, $\mathrm{L}_{\mathrm{pA}}, \mathrm{L}_{\mathrm{pB}}, \mathrm{L}_{\mathrm{p} C}, \mathrm{~L}_{\mathrm{pD}}$ - values read from tables related to the size and weight of parts, difficulty with maneuvering, assembly orientations.

The formula describing the results of the analysis of the $W_{\text {as }}$ feasibility factor according to the Lucas DFA method is:

$$
\begin{gathered}
\mathrm{W}_{\mathrm{as}}=\frac{\mathrm{W}_{\mathrm{m}}+\mathrm{W}_{\mathrm{ad}}}{\mathrm{L}_{\mathrm{kA}}} \\
\mathrm{W}_{\mathrm{m}}=\mathrm{L}_{\mathrm{mA}}+\mathrm{L}_{\mathrm{mB}}+\mathrm{L}_{\mathrm{mC}}+\mathrm{L}_{\mathrm{mD}} \\
\mathrm{W}_{\mathrm{ad}}=\mathrm{L}_{\mathrm{mE}}+\mathrm{L}_{\mathrm{mF}}+\mathrm{S}_{\mathrm{ec}}
\end{gathered}
$$

where: $\mathrm{W}_{\mathrm{as}}$ - assemblability coefficient, $\mathrm{W}_{\mathrm{m}}$ - main activity indicator, $\mathrm{LmA}, \mathrm{LmB}, \mathrm{Lmc}, \mathrm{LmD}$ - values read from tables related to the insertion process, insertion direction and fold, access, $\mathrm{W}_{\text {ad }}$ - additional activities indicator, $\mathrm{LmE}, \mathrm{LmF}, \mathrm{S}_{\mathrm{ec}}$ - values read from tables related to difficulty fit and resistance, additional activities [21].

\subsection{The Boothroyd Dewhurst method}

The method was developed in the late 1970s. by prof. Geoffrey Boothroyd at the University of Massachusetts in Amherst in cooperation with the University of Salford in UK. The method, like the previous one, aims to: reduce the number of components, eliminate rework, use self-positioning and self-embedding components, provide adequate access and unrestricted field of view, ensure ease of 
assemble parts with looseness, minimizing the need for reorientation during assembly, eliminating parts, which cannot be installed incorrectly, maximizing symmetrical parts, if possible, or if not asymmetrical. The method assumes that the part is a permanent or non-permanent element of the assembly process. A subassembly is considered a part of it is added during assembly. Each part has two parameters - thickness and size (adhesives, fluxes, fillers, etc., used to connect parts are not considered parts) - Fig. 3. Thickness is the length of the shortest side of the smallest cuboid that surrounds the element. If the element has a cylindrical or regular polygonal shape, e.g. a section with five or more sides, the thickness is defined as the radius of the smallest cylinder that surrounds the element. The size is the length of the longest side of the smallest cuboid that can surround the part.
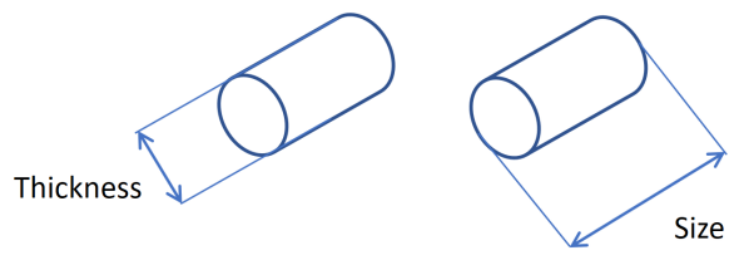

Figure 3. Determining the thickness and size of parts [5]

The next step is to assess the symmetry of the element and determine the number of degrees of rotation around both axes for proper orientation and alignment - Fig. 4 [5].

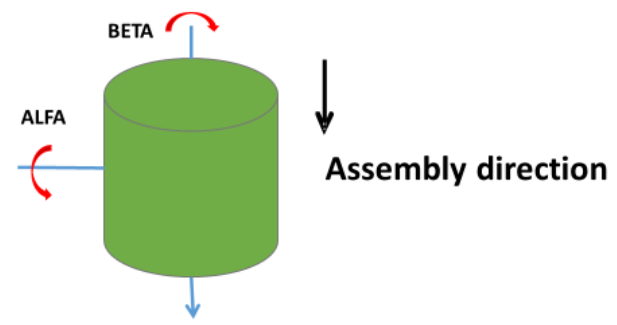

Figure 4. Determining alpha and beta angles [5]

BETA is the symmetry of the part relative to the insertion axis, i.e. the smallest rotation angle for correct insertion. ALFA is the symmetry of the part about the axis perpendicular to the insertion direction - the smallest angle between alternative insertion directions [5] (G. Boothroyd, 1983). After determining the thickness, size, BETA and ALFA angles, the method is shown in Fig. 5.

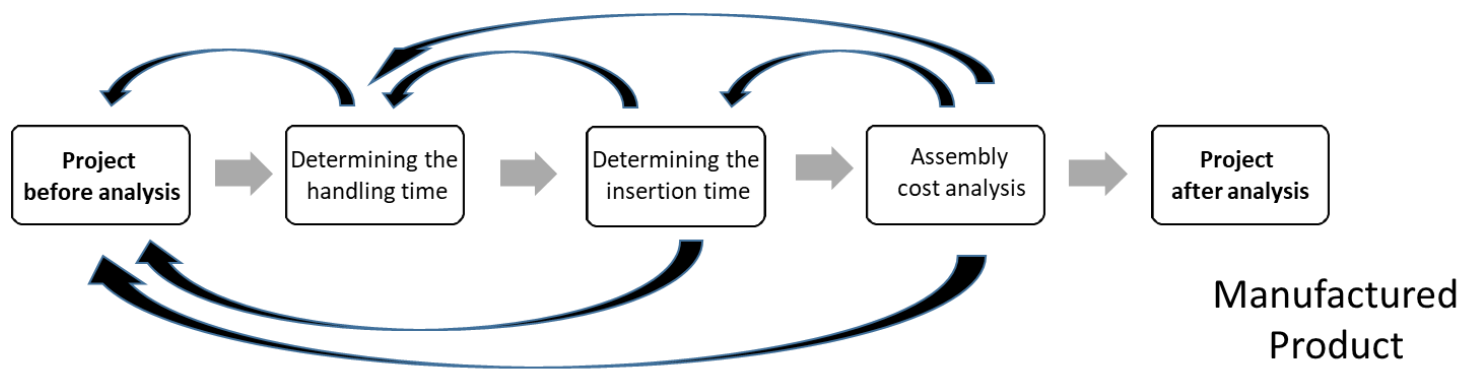

Figura.5. Proceedings in the Boothroyd-Dewhurst for Assembly method

The indexes for handling time and insertion (assembly) time of individual elements are determined. A special table prepared by Boothroyd and Dewhurst serves this purpose. By specifying the time index of element manipulation, you can specify whether the manipulation can be performed: with one hand, one hand with an auxiliary handle, two hands, two hands with mechanical assistance. Knowing the assembly times, you can proceed to process analysis, e.g. whether the number of 
assembled parts should be reduced, replace them other more complex. This method is used to analyze manual assembly, separate variants of the method are used to analyze automatic assembly. The final step is to calculate the sum of the number of operations, the total operation time, the total cost of the operation, the theoretical minimum number of parts and the DFMA index.

$$
L_{o}=l_{o 1}+l_{o 2}+\ldots \ldots+l_{o i}+\ldots \ldots+l_{o n}=\Sigma l_{o i}
$$

where: Lo - number of operations, $l_{o i}$ - assembly operation

$$
T_{o}=\Sigma t_{o i}=I_{m a}+I_{m o}
$$

where: $T_{o}$ - the total operation time, toi - operation time, Ima - time index manipulation operations, Imo - time index assembly operations

$$
K_{o}=\Sigma k_{o i}=\Sigma l_{o i} \cdot k_{o i}
$$

where $\mathrm{K}_{\mathrm{o}}$-cost of the process; $l_{o i}$ - an index (number) process operations; $k_{o i}$-average individual process treatment cost

$$
C_{t}=C_{p e}-C_{a e}
$$

where: $C_{t}$ - the theoretical minimum number of elements; $C_{p e}$ - number of elements before the elimination analysis; $C_{a e}$ - the number of parts eliminated in the analysis of elimination

$$
D F M A_{\text {indeks }}=\left(t_{a} \cdot L_{o}\right) / T_{o} \text {; }
$$

where: DFMAindex - DFMA index; A - the number of parts necessary for the functioning of the product for a large number of parts it can be assumed that: $L_{o}=A$, (the study assumes that $\mathrm{L}_{\mathrm{o}}=\mathrm{A}=\mathrm{C}_{\mathrm{t}}$ ); $t_{a}$ - assembly time of basic ideal part (based on Boothoroyd $t_{a}=3 \mathrm{~s}$ ); $T_{0}$ - the total assembly time of the product).

\section{The project according to the new integrated DFA method based on fuzzy inference}

\subsection{Assumptions for the new DFA method}

The justification for the emergence of a new fuzzy method for assessing the technology of the structure results from the observed lack of flexibility of the described methods of BoothroydDewhurst and Lucas. These methods were created in the 1980s in the conditions of needs of the economy focused on serial and mass production. The current development of the economy and technology means that the modern economic system is characterized by a much greater need for flexibility in terms of production methods: high volume, low volume and unit. The need to create a more flexible method adaptable to the type of production is noticeable[3].

The design process should be determined from the point of view of various usability criteria Fig. 6. The assessment should take into account many other various factors, sales, service, spare parts availability, production series, types of equipment, available assembly techniques, level of automation, cooperative services, possibilities of application commercial components, crew technical culture, etc. In small-lot and serial production conditions, the design process of new product production is based on simplified production documentation[9]. Due to the low production series, production data result from the project are rarely verified at the production stage, while the experience gained from this stage is used in the production projects of new products. In relation to mass production and mass production, particular attention from the point of view of cost criterion is paid to: the possibility to use unified and standardized elements included in the final product, the use of work stations and workshop aids for processing and assembly of various elements included in the products making up the program production and introduction of group machining processes, process phases, group operations for various elements [22]. The newly proposed method use fuzzy inference is characterized by such flexibility $[11,20]$. 


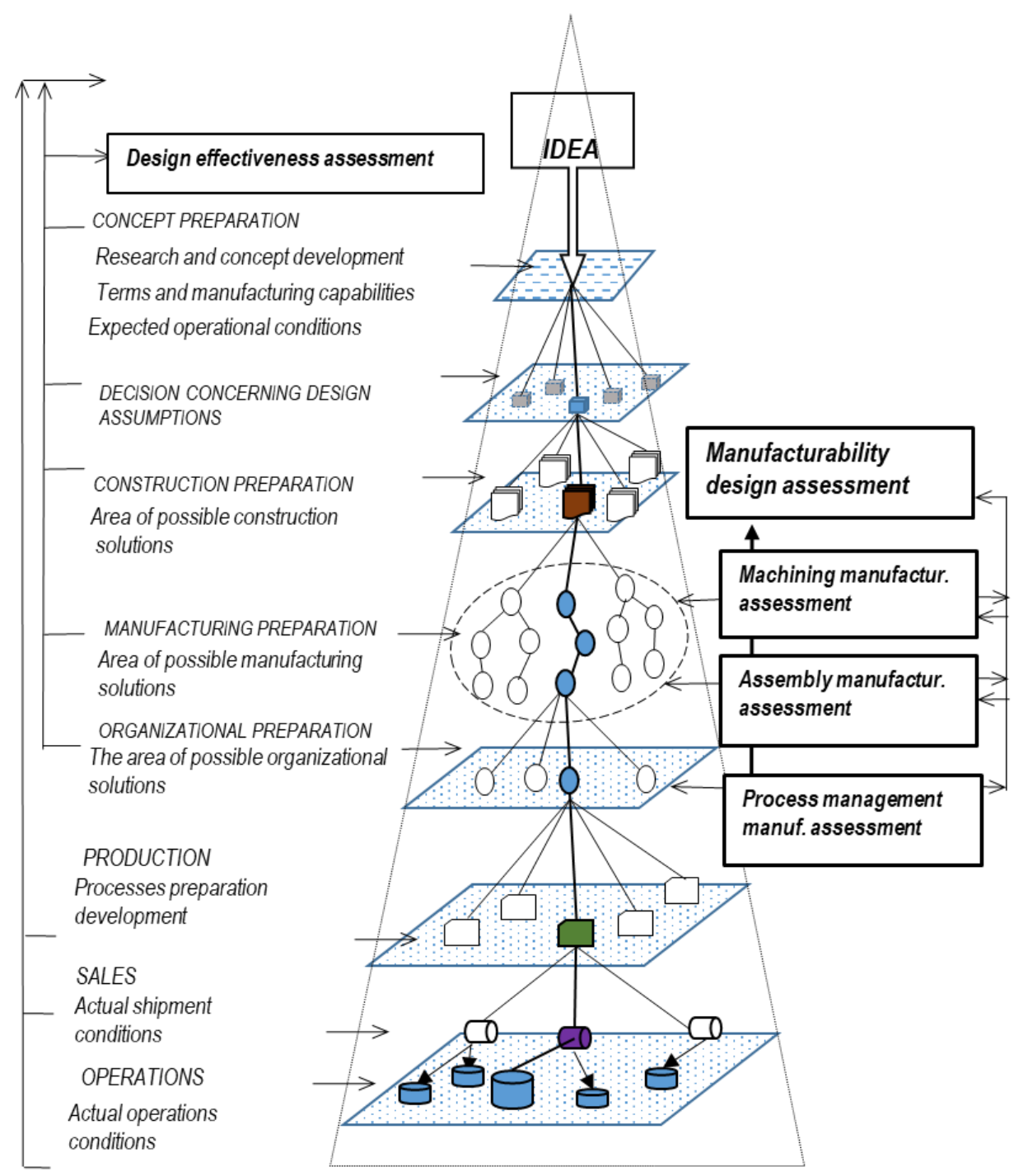

Figure 6. Modified design and development process for the production of a new product

\subsection{The course of the new DFA method}

The product design analysis process is carried out by experts representing as experts: product design, machining process design, assembly process design, quality assurance, product cost analysis, OHS and environmental protection in accordance with Figures 7 and 8.

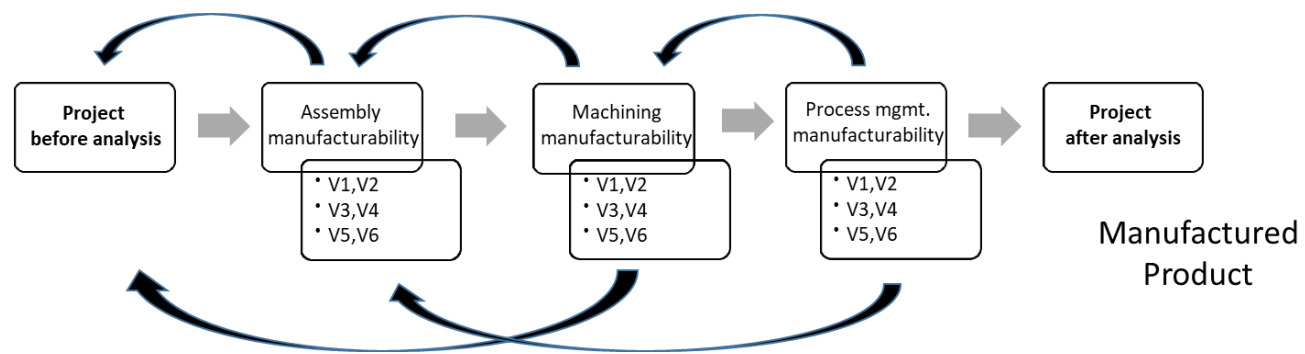

Figure 7. Structural analysis of the structure's technology in the proposed method. 


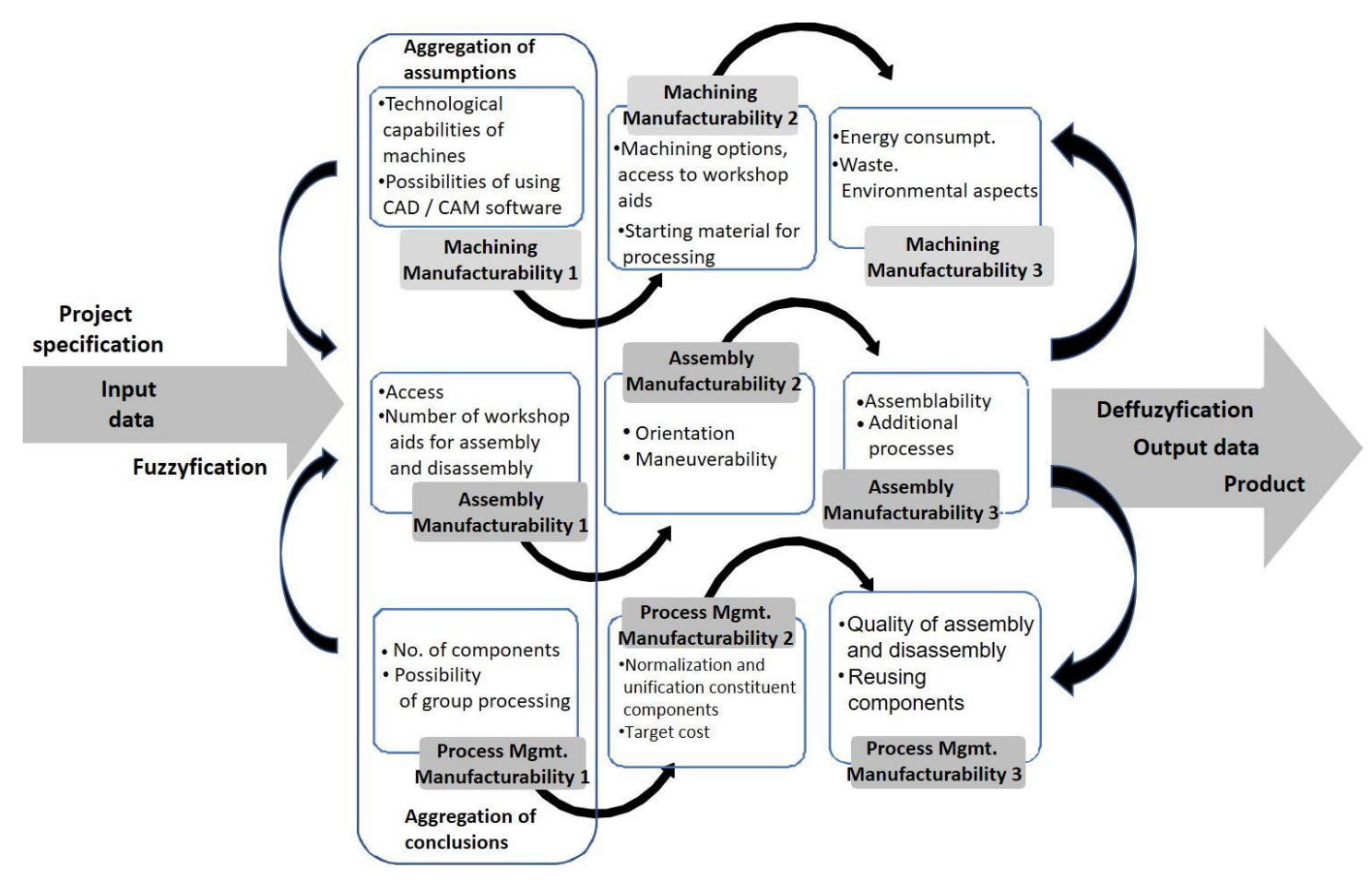

Figure 8. Model of the new DFA method based on three successive stages and sub-stages of fuzzy inference.

Experts determine to use method tables, e.g. Boothroyd or Lucas, in accordance with the order of the process for each component of the product design, make an assessment on a scale of 0 to 100 . Then the process of the machining process and the assembly process are evaluated. The method was developed on the basis of the proposed General Scheme of Technology Assessment and consists of three stages: assessment of machining efficiency, assessment of assembly efficiency, assessment of production organization efficiency[14].

The assessment is related to the set of linguistic variables $\mathrm{Vi}=\{\mathrm{V} 1, \ldots, \mathrm{Vn}\}$, and $\in \mathrm{N}-\{0\}$, defining the input and output criteria of technology. The linguistic variable $\mathrm{Vi}$ is described by a quadrangle:

$$
[\mathrm{Li}, \mathrm{Ti}(\mathrm{L}), \Omega i, \mathrm{Mi}]
$$

where : $\mathrm{Li}_{i}=\left\{\mathrm{L}_{1}, \ldots, \mathrm{Ln}_{\}}\right\}, \mathrm{i} \in \mathrm{N}-\{0\}-$ set of linguistic variable names, $\mathrm{T}_{\mathrm{i}}\left(\mathrm{Li}_{\mathrm{i}}\right)=\left\{\mathrm{T}_{1}\left(\mathrm{~L}_{1}\right), \ldots, \mathrm{T}_{\mathrm{n}}\left(\mathrm{Ln}_{n}\right)\right\}, \mathrm{i}$ $\in \mathrm{N}-\{0\}-$ set of countable determinations of linguistic variables, $\mathrm{tij}=\{\mathrm{t} 11, \mathrm{t} 12, \ldots, \mathrm{tnm}\}$, $\mathrm{i}, \mathrm{j} \in \mathrm{N}-\{0\}, \mathrm{tij} \subset \mathrm{Ti}(\mathrm{Li})$ - set of linguistic values of linguistic variables, $\Omega \mathrm{i}=\{\Omega 1, \ldots, \Omega \mathrm{n}\}$ ,$i \in N-\{0\}$ - set of linguistic ranges of variables $\mathrm{Vi}, \mathrm{Mi}=\{\mathrm{Mi}, \ldots, \mathrm{Mn}\}, \mathrm{i} \in \mathrm{N}-\{0\}$ - set of semantic rules, $\mathrm{mij}=\{\mathrm{m} 11, \mathrm{~m} 12, \ldots, \mathrm{mmn}\}$, and $, \mathrm{j} \in \mathrm{N}-\{0\}, \mathrm{mij} \subset \mathrm{Mi}-$ range of variation in linguistic value tij with an assessment of belonging from 0 to 1 [12].

The assessment of machining processability and subsequent assembly technology assessment correspond to the prototype stage during product design and development, and the assessment of production organization technology corresponds to the plot series and production series during validation and then serial production. The applied variables V1, V2, V3, V4, V5, V6 in the scope of machining technologies, assembly, production organization are shown in Fig. 8. The assessment, depends on the scope of information obtained, can be carried out for individual components of the product, groups of elements, its assemblies or also in a holistic way [12].

\section{Example}

\subsection{Input assumptions}


Based on the analyzes of the above methods of assessment the product's producibility, an improved proprietary approach was proposed in the process of shaping the product's productiveness. The illustration of the presented proposals is presented on the example of a singlestage gear in Fig 9. General purpose gearboxes are designed in the form of a series of types from the point of view of market demand, production costs and delivery time to the customer. The gearbox shown in Fig. 9 was designed in a traditional way (welded body, a large number of bolted joints, etc.).

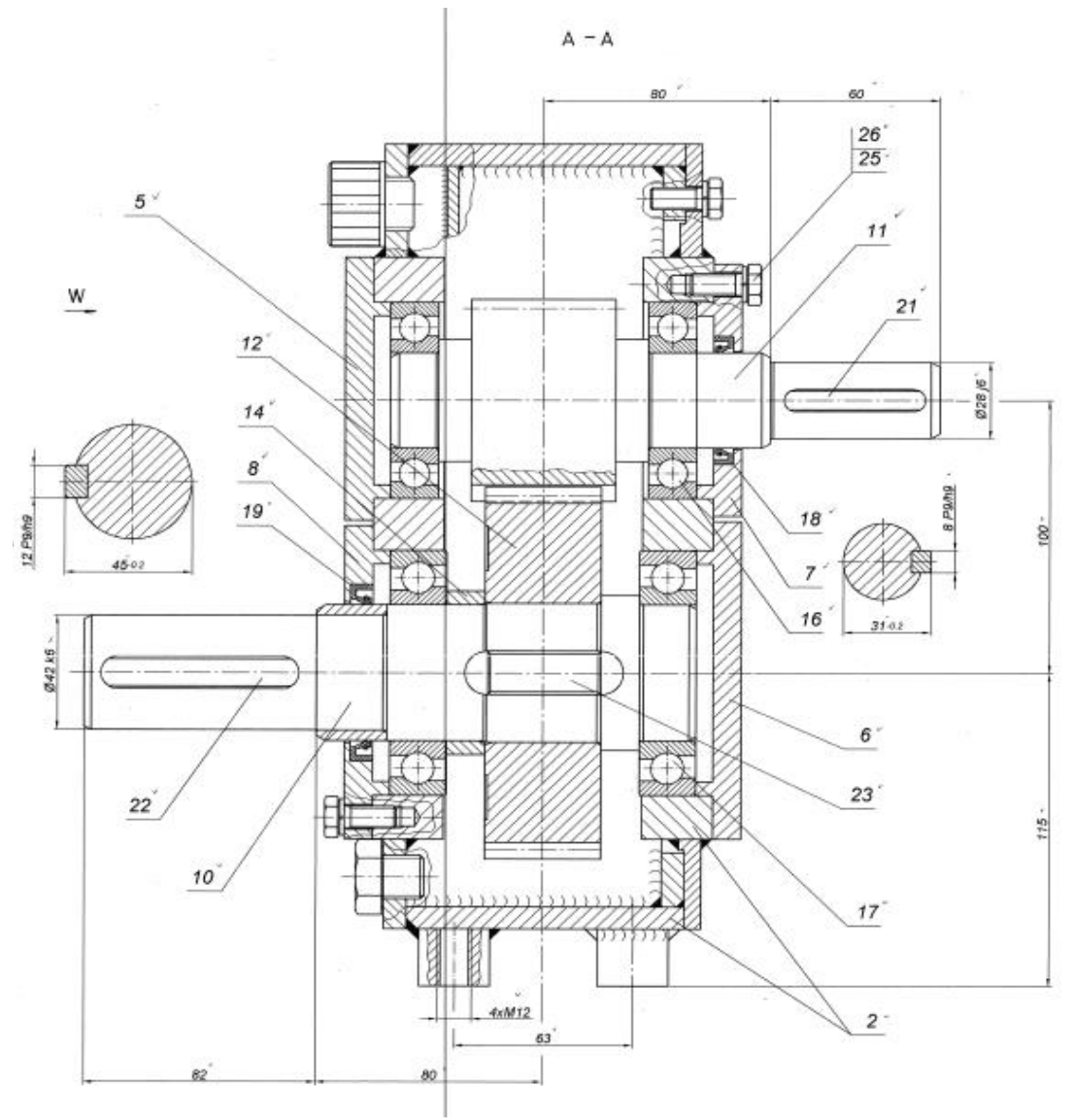

Figure 9. Diagram of the analyzed gearbox, 2- body, 5, 6, 7, 8- bearing caps, 10- shaft, 11-pinion, 12-tooth gear, 14- spacing rings, 17, 16- bearings, 18, 19, - seals, 21, 22, 23- keys, 25, 26-washers, screws.

\subsection{Fuzzy assessment of design for assembly technology}

According to the order of evaluation (Fig. 7), experts assess the efficiency of the process for each stage of the process (on a scale of 0 to 100). To illustrate the course of the procedure, the assessment was carried out for sub-step 1 of the design for assembly efficiency assessment - Fig. 8. The remaining stages and assessments were used to compare the results of the proceedings. The example is presented for one group of elements mounted together - body and cover[8,20].

\section{Assessment of Design for Assembly Technology - sub-step 1}

The component's technology, assuming that it depends on two factors, which are: access, assemblage has been set by experts for: "Access" $=20$, "Number of workshop aids" $=55$. The membership functions of linguistic variables for the given factors are given in Table 2 and 3 , the bases of rules for them are presented in Table 4 and 5.

Table 2. Membership functions in tabular form of linguistic variables for "Access"

\begin{tabular}{|l|l|}
\hline \multicolumn{1}{|c|}{ DESCRIPTION - ACCESS } & Rate \\
\hline $\begin{array}{l}\text { The area is very difficult available, special care/tools/ techniques required to remove } \\
\text { parts without damaging it }\end{array}$ & 0 \\
\hline Limited surface/eyesight, extreme care required to take pictures without damage & 30 \\
\hline
\end{tabular}


The area has limited access, but some can be removed without damage

The area is easy to assemble, lots of hands/tools 60 100

Table 3. Membership functions in tabular form of linguistic variables for " Number of workshop aids"

\begin{tabular}{|l|l|}
\hline \multicolumn{1}{|c|}{ DESCRIPTION - NUMBER OF WORKSHOP AIDS } & \multicolumn{1}{r|}{ Rate } \\
\hline Unnecessary & 0 \\
\hline Easy to grasp & 0 \\
\hline Orientation tools in 1 axis & 30 \\
\hline Orientation tools in 2 axis & 30 \\
\hline Tools in both axes & 60 \\
\hline Medium difficult tools & 60 \\
\hline Heavy nesting or tangling & 60 \\
\hline Requires a tool to capture & 60 \\
\hline Requires two people & 100 \\
\hline Requires service equipment & 100 \\
\hline
\end{tabular}

Table 4. Rule base for "Access"

\begin{tabular}{|c|c|c|c|c|}
\hline \multicolumn{5}{|c|}{ ACCESS } \\
\hline & Very hard & Limited & Moderately limited & Easy \\
\hline 0 & 1 & 0 & 0 & 0 \\
\hline 30 & 0 & 1 & 0 & 0 \\
\hline 60 & 0 & 0 & 1 & 0 \\
\hline 100 & 0 & 0 & 0 & 1 \\
\hline
\end{tabular}

Table 5. Rules database for "Number of workshop aids"

\begin{tabular}{|c|c|c|c|c|}
\hline \multicolumn{5}{|c|}{ NUMBER OF AIDS } \\
\hline & Easy & $\begin{array}{c}\text { Requires } \\
\text { orientation }\end{array}$ & Heavy or tools & $\begin{array}{c}\text { Two people or } \\
\text { equipment }\end{array}$ \\
\hline 0 & 1 & 0 & 0 & 0 \\
\hline 30 & 0 & 1 & 0 & 0 \\
\hline 60 & 0 & 0 & 1 & 0 \\
\hline 100 & 0 & 0 & 0 & 1 \\
\hline
\end{tabular}

The "Access" factor is described by the formulas:

$$
\begin{gathered}
\mu_{\text {VERY HARD }}(x)=\left\{\begin{array}{rr}
\frac{30-x}{30-0} & \text { dla } 0<x<30 \\
x=0 & \text { dla } 30 \leq x \leq 100
\end{array}\right. \\
\mu_{\text {LIMITED }}(x)=\left\{\begin{array}{cc}
\frac{x}{30-0} & \text { dla } 0<x<30 \\
\frac{60-x}{60-30} & \text { dla } 30<x<60 \\
x=0 & \text { dla } 60 \leq x \leq 100
\end{array}\right. \\
\mu_{\text {MODERATELY LIMITED }}(x)=\left\{\begin{array}{cc}
x=0 & \text { dla } x \leq 30 \\
\frac{x-30}{60-30} & \text { dla } 30<x<60 \\
\frac{100-x}{100-60} & \text { dla } 60<x<100
\end{array}\right. \\
\mu_{\text {EASY }}(x) \quad=\left\{\begin{array}{cc}
x=0 & \text { dla } x \leq 60 \\
\frac{x-60}{100-60} & \text { dla } 60<x<100
\end{array}\right.
\end{gathered}
$$


Table 6. Fuzzy rules table for Design for Assembly Technology - sub-step 1.

\begin{tabular}{|c|c|c|c|c|c|c|}
\hline 1 & If & Easy access & And & $\begin{array}{l}\text { Numer of aids two } \\
\text { people or equipment }\end{array}$ & Then & $\begin{array}{l}\text { DFA Technology } 1 \text { - } \\
\text { medium-low }\end{array}$ \\
\hline 2 & If & Easy access & And & $\begin{array}{l}\text { Heavy Numer of aids } \\
\text { or tools }\end{array}$ & Then & $\begin{array}{c}\text { DFA Technology } 1 \text { - } \\
\text { average }\end{array}$ \\
\hline 3 & If & Easy access & And & $\begin{array}{c}\text { Maneuverability } \\
\text { requires orientation }\end{array}$ & Then & $\begin{array}{c}\text { DFA Technology } 1 \text { - } \\
\text { High }\end{array}$ \\
\hline 4 & If & Easy access & And & Easy Numer of aids & Then & $\begin{array}{c}\text { DFA Technology } 1 \text { - } \\
\text { High }\end{array}$ \\
\hline 5 & If & $\begin{array}{c}\text { Medium } \\
\text { restricted ccess }\end{array}$ & And & $\begin{array}{c}\text { Numer of aids two } \\
\text { people or equipment }\end{array}$ & Then & $\begin{array}{c}\text { DFA Technology } 1 \text { - } \\
\text { Low }\end{array}$ \\
\hline 6 & If & $\begin{array}{c}\text { Medium } \\
\text { restricted ccess }\end{array}$ & And & $\begin{array}{l}\text { Heavy Numer of aids } \\
\text { or tools }\end{array}$ & Then & $\begin{array}{l}\text { DFA Technology } 1 \text { - } \\
\text { medium-low }\end{array}$ \\
\hline 7 & If & $\begin{array}{l}\text { Medium } \\
\text { restricted ccess }\end{array}$ & And & $\begin{array}{c}\text { Numer of aids requires } \\
\text { orientation }\end{array}$ & Then & $\begin{array}{c}\text { DFA Technology } 1 \text { - } \\
\text { average }\end{array}$ \\
\hline 8 & If & $\begin{array}{c}\text { Medium } \\
\text { estricted access }\end{array}$ & And & Easy Numer of aids & Then & $\begin{array}{c}\text { DFA Technology } 1 \text { - } \\
\text { average }\end{array}$ \\
\hline 9 & If & Limited access & And & $\begin{array}{c}\text { Numer of aids two } \\
\text { people or equipment }\end{array}$ & Then & $\begin{array}{c}\text { DFA Technology } 1 \text { - } \\
\text { Low }\end{array}$ \\
\hline 10 & If & Limited access & And & $\begin{array}{l}\text { Heavy Numer of aids } \\
\text { or tools }\end{array}$ & Then & $\begin{array}{l}\text { DFA Technology } 1 \text { - } \\
\text { medium-low }\end{array}$ \\
\hline 11 & If & Limited access & And & $\begin{array}{c}\text { Numer of aids requires } \\
\text { orientation }\end{array}$ & Then & $\begin{array}{c}\text { DFA Technology } 1 \text { - } \\
\text { average }\end{array}$ \\
\hline 12 & If & Limited access & And & Easy Numer of aids & Then & $\begin{array}{c}\text { DFA Technology } 1 \text { - } \\
\text { average1 }\end{array}$ \\
\hline 13 & If & $\begin{array}{c}\text { Access is very } \\
\text { difficult }\end{array}$ & And & $\begin{array}{c}\text { Numer of aids two } \\
\text { people or equipment }\end{array}$ & Then & $\begin{array}{c}\text { DFA Technology } 1 \text { - } \\
\text { Low }\end{array}$ \\
\hline 14 & If & $\begin{array}{c}\text { Access is very } \\
\text { difficult }\end{array}$ & And & $\begin{array}{l}\text { Heavy Numer of aids } \\
\text { or tools }\end{array}$ & Then & $\begin{array}{c}\text { DFA Technology } 1 \text { - } \\
\text { Low }\end{array}$ \\
\hline 15 & If & $\begin{array}{c}\text { Access is very } \\
\text { difficult }\end{array}$ & And & $\begin{array}{c}\text { Numer of aids requires } \\
\text { orientation }\end{array}$ & Then & $\begin{array}{c}\text { DFA Technology } 1 \text { - } \\
\text { medium-low }\end{array}$ \\
\hline 16 & If & $\begin{array}{c}\text { Access is very } \\
\text { difficult }\end{array}$ & And & Easy Numer of aids & Then & $\begin{array}{c}\text { DFA Technology } 1 \text { - } \\
\text { average }\end{array}$ \\
\hline
\end{tabular}

For the body, for the values "Access" = 20 and "Maneuverability" = 55 on the basis of Fig. 9, according to the "min" inference rule described above, the following rules are active:

- Rule 14 Very Difficult Access and Maneuverability Heavy or Tools to a degree of min $(0.33,0.17)$ $=0.17$ (medium technology)

- Rule 15 Very Difficult Access and Maneuverability Requires Minimal Orientation $(0.33,0.833)=$ 0.33 (medium technology)

- Rule 10 Limited Access and Maneuverability Heavy or Tools to a degree of $\min (0.67,0.17)=0.17$ (low technology)

- Rule 11 Limited Access and Maneuverability Requires Min (0.67, 0.833) orientation = 0.67 (medium technology)

After taking into account rules 10, 11, 14 and 15, in Mamadani's inference there is a maximum operation as an operator of the aggregation of inference results obtained on the basis of individual rules, therefore rules 10 and 15 which have the same "medium-low" rating, we choose MAX so we activate rule 15 .

Aggregation of rules for assembly technology in sub-step 1 is given in Fig. 10. 


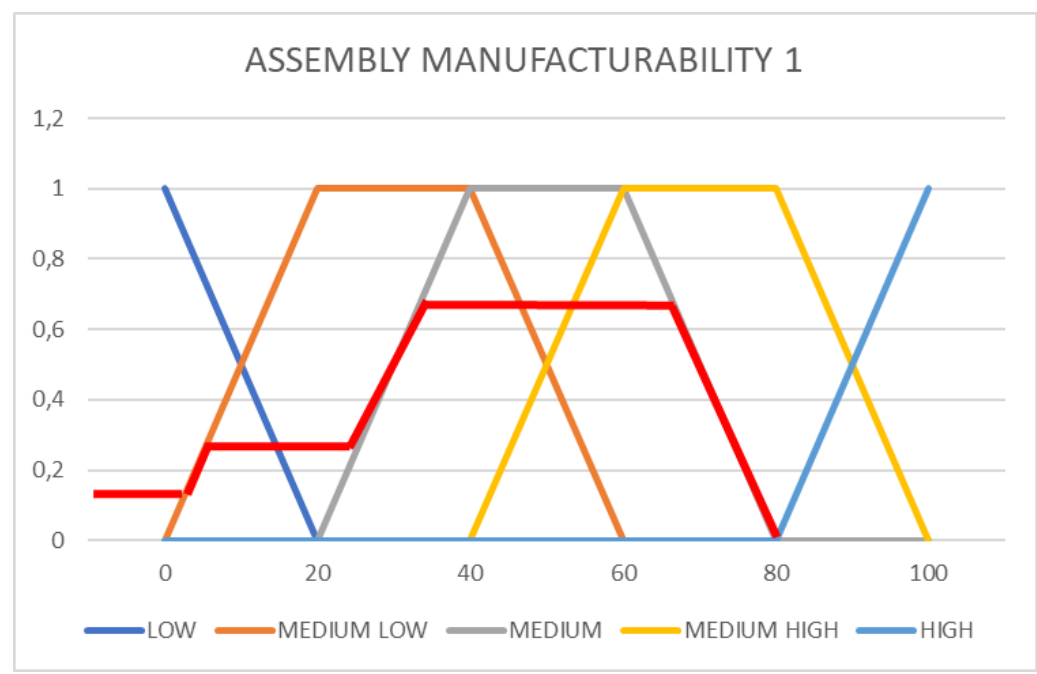

Figure 10. Aggregation of rules Design for Assembly Technology - sub-step 1.

The next action is Defuzzyfication (sharpening) of the parameter value to provide the predicted factor value. The basis of action is the resulting membership function represented in a fuzzy form, while the inference should end with providing a specific numerical value, hence the need to sharpen. Various methods can be used to carry out this process: Center of gravity, Average maximum, First maximum, Last maximum. The centre of gravity method was selected:

$$
\begin{gathered}
\left\{\begin{array}{c}
y=\frac{x}{20} \\
y=0,17
\end{array} ; \quad 0,17=\frac{x}{20} ; \quad x=20 \cdot 0,17=3,4\right. \\
\left\{\begin{array}{l}
y=\frac{x}{20} \\
y=0,33
\end{array} ; \quad 0,33=\frac{x}{20} ; \quad x=20 \cdot 0,33=6,6\right. \\
\left\{\begin{array}{l}
y=\frac{80-x}{80-60} ; \\
y=0,67
\end{array} \quad 0,67=\frac{80-x}{20} ; \quad x=80-13,4=66,6\right. \\
\left\{\begin{array}{l}
y=\frac{x-20}{40-20} ; \\
y=0,33 \\
x-20
\end{array} \quad 0,33=\frac{x-20}{20} ; \quad x=20 \cdot 0,33+20=26,6\right. \\
y=0,67 \quad 0,67=\frac{x-20}{20} ; \quad x=20 \cdot 0,67+20=33,4
\end{gathered}
$$

Deffuzified Center of Gravity value)

$$
\begin{gathered}
r=\frac{r_{1}}{r_{2}}=\frac{\int_{0}^{80} y \cdot \mu_{B^{\prime}}(y) d y}{\int_{0}^{80} \mu_{B^{\prime}}(y) d y}= \\
r=\frac{\int_{0}^{3,4} y \cdot 0,17 d y+\int_{3,4}^{6,6} y \cdot \frac{y}{20} d y+\int_{26,6}^{33,4} y \cdot \frac{y-20}{20} d y+\int_{6,6}^{26,6} y \cdot 0,33 d y+\int_{33,4}^{66,6} y \cdot 0,67 d y+\int_{66,6}^{80} y \cdot \frac{80-y}{20} d y}{\int_{0}^{80} \mu_{B^{\prime}}(y) d y}
\end{gathered}
$$

gdzie:

$$
\begin{gathered}
r_{1}=\left[\frac{y^{2}}{12}\right]{ }_{0}^{3,4}+\left[\frac{y^{3}}{60}\right]{ }_{3,4}^{6,6}+\left[\frac{y^{2}}{6}\right]_{6,6}^{26,6}+\left[\frac{1}{20} \cdot\left(\frac{y^{2}}{3}-10 y^{2}\right)\right]_{26,6}^{33,4}+\left[\frac{y^{2}}{3}\right] \underset{33,4}{66,6}+\left[\frac{1}{20} \cdot\left(40 y^{2}-\frac{y^{2}}{3}\right)\right]_{66,6}^{80} \\
=0,96+4,14+110,67+103,31+1106,67+319,02=1644,76 \\
r_{2}=\int_{0}^{80} \mu_{B^{\prime}}(y) d y=P_{1}+P_{2}+P_{3} \\
\quad P_{1}=(6,6-0) \cdot 0,17=1,1 ; \quad P_{2}=(20-0) \cdot 0,33=6,6 ; \quad P_{3}=\frac{[60+33,2] \cdot 0,67}{2}=31,22 \\
r_{2}=\int_{0}^{80} \mu_{B^{\prime}}(y) d y=1,1+6,6+31,22=38,9 \\
\quad r=\frac{1644,76}{38,9}=42,2
\end{gathered}
$$


The technology assessment for the 1st stage assumes for the adopted access assessment - 20 and the number of workshop aids - 55 value $\sim 40$.

\section{Assessment of Design for Assembly Technology - sub-step 2}

The component's technology is determined, assuming that it depends on two factors, which are: orientation, manoeuvrability. The expert group made the following assessment: orientation - 10, manoeuvrability $=35$.

Table 7. Membership functions in tabular form of linguistic variables for Orientation

\begin{tabular}{|l|c|}
\hline \multicolumn{1}{|c|}{ DESCRIPTION- ORIENTATION } & Rate \\
\hline Does not require orientation & $\mathbf{1 0 0}$ \\
\hline Requires orientation in the assembly axis & $\mathbf{6 0}$ \\
\hline Requires orientation perpendicular to the assembly axis & $\mathbf{3 0}$ \\
\hline $\begin{array}{l}\text { Requires orientation in the assembly axis and perpendicular to the assembly } \\
\text { axis }\end{array}$ & $\mathbf{0}$ \\
\hline
\end{tabular}

Table 8. Membership functions in tabular form of linguistic variables for Maneuverability

\begin{tabular}{|l|c|}
\hline DESCRIPTION - MANEUVERABILITY & Rate \\
\hline Easy to grasp (one hand) & 0 \\
\hline Easy to grip (BH) & 0 \\
\hline Change orientation (OH) & 30 \\
\hline Change orientation (BH) & 30 \\
\hline Slippery & 60 \\
\hline Flexible or small & 60 \\
\hline Heavy nesting or tangling & 60 \\
\hline Requires a tool to capture & 60 \\
\hline Requires two people & 100 \\
\hline Requires service equipment & 100 \\
\hline
\end{tabular}

Table 9. Rule base for Orientation

\begin{tabular}{|c|c|c|c|c|}
\hline \multicolumn{5}{|c|}{ ORIENTATION } \\
\hline & Both axis & Perpendicular to axis & In the axis & None \\
\hline 0 & 1 & 0 & 0 & 0 \\
\hline 30 & 0 & 1 & 0 & 0 \\
\hline 60 & 0 & 0 & 1 & 0 \\
\hline 100 & 0 & 0 & 0 & 1 \\
\hline
\end{tabular}

Table 10. Rule base for manoeuvrability

\begin{tabular}{|c|c|c|c|c|}
\hline \multicolumn{5}{|c|}{ MANOEUVRABILITY } \\
\hline & Easy & Requires orientation & Heavy or tools & Two people or equipment \\
\hline 0 & 1 & 0 & 0 & 0 \\
\hline 30 & 0 & 1 & 0 & 0 \\
\hline
\end{tabular}




\begin{tabular}{|c|c|c|c|c|}
60 & 0 & 0 & 1 & 0 \\
\hline 100 & 0 & 0 & 0 & 1 \\
\hline
\end{tabular}

Aggregation of rules for Assembly Technology 2 is shown in Figure 10

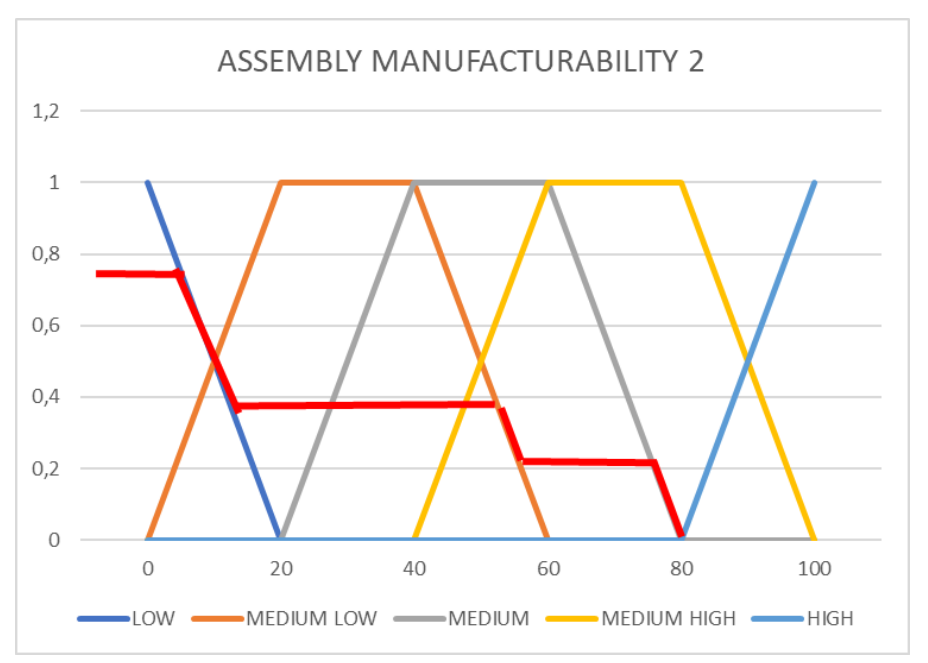

Figure 11. Aggregation of rules for Assembly Technology 2

Technology 2 takes the value for Orientation 10 and Maneuverability 35 the value 31 .

\section{Assessment of Design fo Assembly Technology - sub-step 3}

The 3 component technology is determined, assuming that it depends on two factors, which are: Assemblability, Processes. The expert group made the following assessment: assemblability $=20$, processes $=35$.

Table 11. Membership functions in tabular form of linguistic variables for Assemblability

\begin{tabular}{|l|c|}
\hline DESCRIPTION-ASSEMBLABILITY & Rate \\
\hline Difficult access and blind assembly & 0 \\
\hline Special equipment & 30 \\
\hline Requires two hands & 60 \\
\hline No difficulty & 100 \\
\hline
\end{tabular}

Table 12. Membership functions in tabular form of linguistic variables for Processes

\begin{tabular}{|l|c|}
\hline DESCRIPTION-PROCESSES & Rate \\
\hline Place part & 100 \\
\hline Snap-fit & 100 \\
\hline Light interference & 60 \\
\hline Pressed into & 60 \\
\hline Screw on by hand & 60 \\
\hline Hand tool screw & 30 \\
\hline Screw on with a power tool & 30 \\
\hline Nitowanie & 30 \\
\hline Zaciskanie & 30 \\
\hline Soldering & 0 \\
\hline
\end{tabular}




\begin{tabular}{|l|c|}
\hline Welding & 0 \\
\hline
\end{tabular}

Aggregation of rules for Design fo Assembly Technology 3 presents Fig. 12

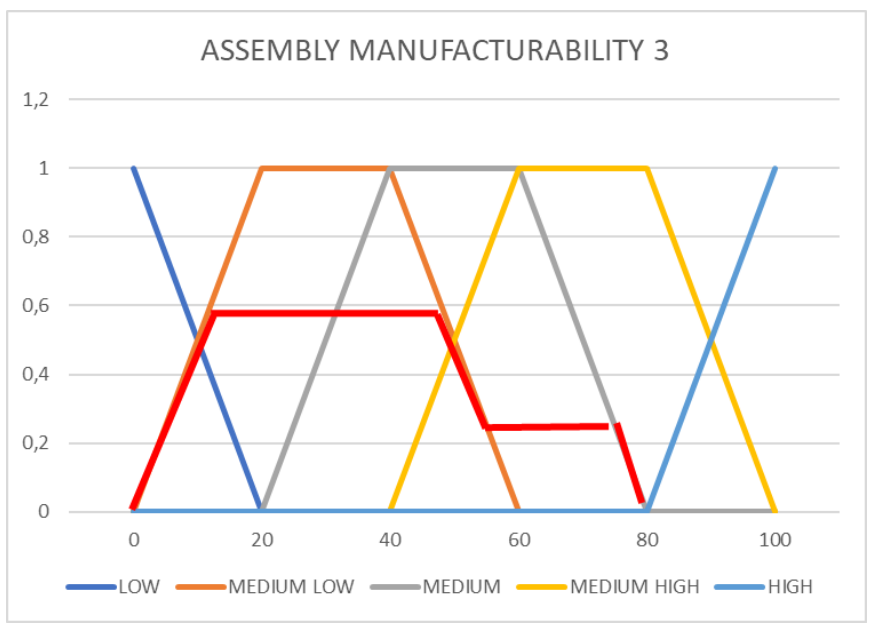

Figure 12. Aggregation of rules for Design for Assembly Technology 3

The technological assessment for the 3rd stage takes for the adopted assessment of Montability - 70 and Joining processes - 10 equal to -36 .

\section{Comparison of the use of methods on the example of a gear fragment - a drive shaft set}

In the study, the indicators of the assessment of the constructionality of the structure were determined for the sample product presented in Fig. 9. As a result of the analysis after the proposed changes, the new form of the gear structure change is illustrated in Fig. 13.

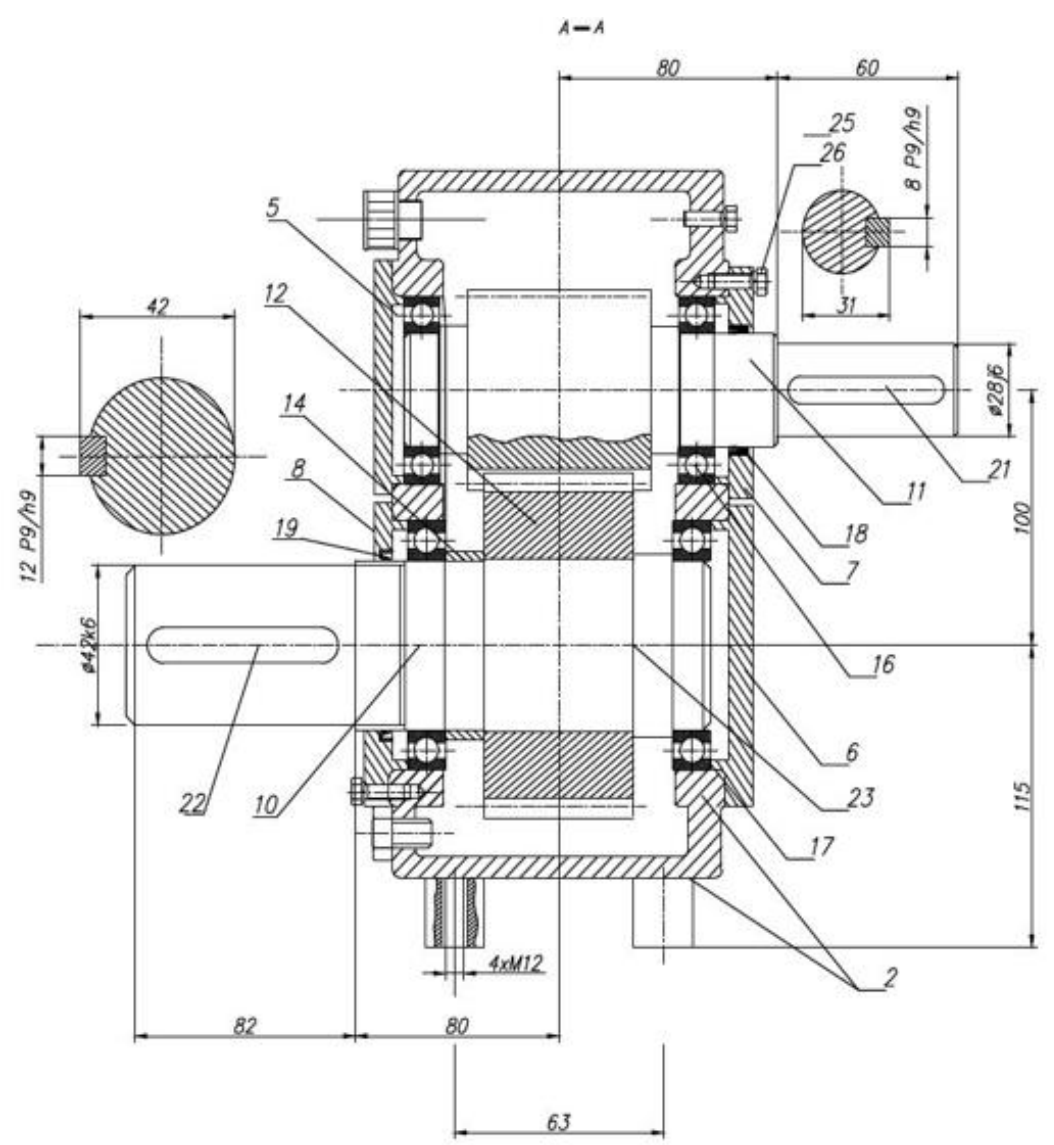

Figure 13. Construction form of the gearbox after the changes have been made 


\section{Conclusions and comments}

In standard technology analyzes according to B\&D and Lucas DFA, it is associated with a reduction in the number of components that have no significant effect on the product's functions or their change consisting in improvement in terms of assembly time and costs. In the traditional arrangement of the above mentioned the methods are oriented towards mass production. The proposed proprietary method based on the analysis of the obtained values of the parameters of the assessment of the efficiency of the entire process enables

- unification of components, application of group processing methods, standardization of machining and assembly operations, and thus saving of investment in machines and shorter overall assembly time, shortening of times, elimination of errors, reduction of process costs

- taking into account, in addition to assembly, many other various factors, e.g. availability of spare parts, production seriality, production conditions in the form of equipment types, available assembly techniques, level of automation, scope of external cooperation orders

- the method can be used for smaller series of manufactured products,

- assessment of technology in the form of given indicators and coefficients should be carried out by experts with extensive production experience,

- arousing designers' creativity when designing new products, rationalizing works at the stage of improving and expanding the range of implemented production.

The presented method is universal. The use of fuzzy logic gives the opportunity to express incomplete and uncertain information in natural language, in a simple way for humans based on expert knowledge and empirical data. The method takes into account the analysis of the production process in a holistic way.

\section{References}

1. Akao Y.: Quality function deployment (QFD). Integrating customer requirements into product design. 1990. Tom 369.

2. Andreasen M. M., Kähler S.: Lund Design for assembly. Lund: Ifs., 1988. Tom Ifs.

3. Battaïa, O., Dolgui, A., Heragu, S. S., Meerkov, S. M., \& Tiwari, M. K. (2018). Design for manufacturing and assembly/disassembly: joint design of products and production systems, https://doi.org/10.1080/00207543.2018.1549795, Online ISSN: 1366-588X

4. Boothroyd G., Dewhurst Design for Assembly. A Designers Handbook, 1983.

5. Boothroyd G.: Product design for manufacture and assembly. Computer-Aided Design. NJ: Elsevier, 1994. Nr 26(7), s. 505-520.

6. Boothroyd, G., Dewhurst, P., \& Knight, W. A. (2010). Product Design for Manufacture and Assembly, III., no. 1. New York: Taylor \& Francis Group.

7. Brzeziński M.: Organizacja I sterowanie produkcją. Agencja Wydawnicza Placet, Warszawa 2002.

8. Ebro, M., \& Howard, T. J. (2016). Robust design principles for reducing variation in functional performance. Journal of Engineering Design, 27(1-3), 75-92, https://doi.org/10.1080/09544828.2015.1103844, Online ISSN: 1466-1837

9. Esterman, M., \& Kamath, K. (2010, January). Design for Assembly Line Performance: The Link Between DFA Metrics and Assembly Line Performance Metrics. In ASME 2010 International Design Engineering Technical Conferences and Computers and Information in Engineering Conference (pp. 73-84). American Society of Mechanical Engineers Digital Collection, https://doi.org/10.1115/DETC2010-28339, ISBN: 978-0-7918-4414-4

10. Evans J. R. I Lindsay W. The management and control of quality South. 1999.

11. Henriques E., Pecas P., Silva A. (Eds.). (2013). Technology and manufacturing process selection: The product life cycle perspective. Springer Science \& Business Media, ISBN 978-1-4471-5543-0

12. Kacprzyk J., Pedrycz W. (Eds.). (2015). Springer handbook of computational intelligence. Springer., ISBN: 978-3-662-43504-5

13. Kehoe D.: Acceptance sampling. // The Fundamentals of Quality Management. - : Springer Netherlands, 1996, s. 226-227. 
14. Liu, H. J., Tong, X. Y., Lv, S. L., \& Fan, Q. M. (2012). Design for manufacture and integrated manufacturability evaluation system. In Advanced Materials Research (Vol. 476, pp. 2567-2570). Trans Tech Publications Ltd, https://doi.org/10.4028/www.scientific.net/amr.476-478.2567, ISSN: 1662-8985

15. Lock Project Management. Ninth Edition. Hampshire, Great Britain: Gower Publishing Ltd, 2009.

16. Matuszek J., Seneta T.: Algorytmizacja procesu wdrażania nowego produktu w warunkach wielkoseryjnej produkcji. Mechanik. 2016, nr 7, s. 755-757.

17. Matuszek J: Inżynieria Produkcji. Wydawnictwo Politechniki Łódzkiej Filii w Bielsku-Białej, BielskoBiała 2000.

18. Miles B.L.: Design for Assembly - a key element within Design for Manufacture - Proc Inst Mech Eng, 1989. - No. 1: strony 29-38. - ISSN 0954-4070.

19. Palady P. I Olyai The status quo's failure in problem-solving. // Quality progress. - 2002. - Tom 35(8). strony 34-34.

20. Shetty, D. and Ali, A. (2015), "A new design tool for DFA/DFD based on rating factors", Assembly Automation, Vol. 35 No. 4, pp. 348-357. https://doi.org/10.1108/AA-11-2014-088, ISSN: 0144-5154

21. Swift, Ken G. Knowledge-based design for manufacture. Prentice-Hall, Inc., 1987. ISBN:978-0-13516569-0

22. Whitney D.E., Mechanical Assemblies - their design manufacture and role in product development: Oxford University Press, 2004. - 0-19-515782-6.

23. Yang K. I El-Haik B.S.: Design for six sigma. New York:: Mcgraw-Hill., 2003. - s. 184-186. 